\title{
Bioresponsive cancer-targeted polysaccharide nanosystem to inhibit angiogenesis
}

This article was published in the following Dove Press journal:

International Journal of Nanomedicine

10 October 2017

Number of times this article has been viewed

Fang Yang

Xueyang Fang

Wenting Jiang

Tianfeng Chen

Department of Chemistry, Jinan University, Guangzhou, China
Correspondence: Fang Yang;

Tianfeng Chen

Department of Chemistry, Jinan

University, 60I Huangpu Road,

Guangzhou 510632, China

Tel +862085220223

Fax +86 $208522 \quad$ I263

Email tyoung@jnu.edu.cn;

tchentf@jnu.edu.cn
Abstract: With many desirable features, such as being more effective and having multiple effects, antiangiogenesis has become one of the promising cancer treatments. The aim of this study was to design and synthesize a new targeted bioresponsive nanosystem with antiangiogenesis properties. The mUPR@Ru(POP) nanosystem was constructed by the polymerization of Ulva lactuca polysaccharide and $N$-isopropyl acrylamide, decorated with methoxy polyethylene glycol and Arg-Gly-Asp peptide, and encapsulated with anticancer complex $[\mathrm{Ru}(\mathrm{phen}) 2 \mathrm{p}$ $\mathrm{MOPIP}]\left(\mathrm{PF}_{6}\right)_{2} \cdot 2 \mathrm{H}_{2} \mathrm{O}$. The nanosystem was both $\mathrm{pH}$ responsive and targeted. Therefore, the cellular uptake of the drug was greatly improved. Moreover, the mUPR@Ru(POP) had strong suppressive effects against vascular endothelial growth factor (VEGF)-induced angiogenesis through apoptosis. The mUPR@Ru(POP) significantly inhibited VEGF-induced human umbilical vein endothelial cell migration, invasion, and tube formation. These findings have presented new insights into the development of antiangiogenesis drugs.

Keywords: polysaccharide nanosystem, antiangiogenesis, cancer-targeted, bioresponsive

\section{Introduction}

It was reported that the overall cancer death rate dropped 25\% from 1991 to 2014 in the USA. ${ }^{1}$ But lots of cancers are hardly cured, and some are still very difficult to treat. Chemotherapy, a common cancer treatment to attack cancer cells, ${ }^{2}$ can induce severe side effects that may influence a person's quality of life. ${ }^{3}$ Targeting angiogenesis represents a novel strategy for the development of anticancer therapies. ${ }^{4,5}$ Both chemotherapy and antiangiogenesis are systemic treatments, but antiangiogenesis drugs work on where new blood vessels are forming. ${ }^{6,7}$ Therefore, they do not induce severe side effects that chemotherapy does. ${ }^{8}$ Antiangiogenesis was proposed in the early 1970s, but until 2004 the first antiangiogenesis drug, Avastin (bevacizumab), was approved by the US Food and Drug Administration (FDA) to treat colon cancer. Bevacizumab is a monoclonal antibody which targets vascular endothelial growth factor (VEGF). It has been established that VEGF is a key driver of sprouting angiogenesis and is overexpressed in most solid cancers. Several other antiangiogenesis drugs have since been approved by the FDA, such as Erbitux (cetuximab), Vectibix (panitumumab), Herceptin (trastuzumab), Tarceva (erlotinib), Nexavar (sorafenib), and Sutent (sunitinib). ${ }^{9}$ Some of them are orally active drugs. Antiangiogenesis drugs have become an important part of treatment for many types of cancer.

Ulva lactuca, also known as sea lettuce, is an edible green alga in the division Chlorophyta. Sea lettuce, a food for humans, is eaten raw in salads and cooked in soups. It is a soluble dietary fiber and has high content of protein and high concentrations of iron as well as a variety of vitamins and minerals. It was reported that 
U. lactuca polysaccharides contained glucose, glucuronic acid, xylose, rhamnose, and sulfate groups. Ulva lactuca (UL) polysaccharide exhibited antiviral, anti-peroxidative and anti-hyperlipidemic properties. ${ }^{10,11}$ Polysaccharides, as functionalizing agents, have been widely used in cancer nanotechnology because of their excellent biocompatibility, stability, nontoxicity, etc. ${ }^{5}$ The nanomaterials decorated by polysaccharides exhibited enhanced cell-permeating and cancer-targeting abilities. ${ }^{12}$ Therefore, in this study, the nanosystem was originally synthesized by the polymerization of $N$-isopropyl acrylamide (NIPAM) and UL polysaccharide.

It was reported that the newer antiangiogenesis drugs also attacked tumor cells themselves. ${ }^{13,14}$ The use of antiangiogenesis drugs in conjunction with irradiation and other chemotherapeutic drugs has led to improved treatment outcomes. ${ }^{15,16}$ It is the goal of scientists to design new drugs that are more effective and have multiple effects. In the years to come, such drugs may blur the line between antiangiogenesis drugs and other cancer treatments. In this study, our goal was to design a targeted antiangiogenic nanosystem, which is also $\mathrm{pH}$ responsive. ${ }^{17}$ Drug delivery systems with a $\mathrm{pH}$ response have been widely used, because they can swell and shrink in different $\mathrm{pH}$ condition so as to achieve targeted drug delivery and efficient drug release in cancer cells. ${ }^{18,19}$ The Arg-Gly-Asp (RGD) peptide, an excellent targeting reagent, can recognize the integrin receptor which is overexpressed in a lot of human tumor cells and is able to bind to both tumor cells and endothelial cells. $^{20}$ Therefore, this $\mathrm{pH}$-responsive nanosystem was also decorated with RGD peptide to achieve targeted drug delivery.

In this study, we designed a novel mUPR@Ru(POP) antiangiogenic nanosystem. The polyelectrolyte core of the nanosystem was constructed by the polymerization of U. lactuca polysaccharide and NIPAM and decorated with RGD peptide and methoxy polyethylene glycol (mPEG). The anticancer complex $\mathrm{Ru}(\mathrm{POP})$ ([Ru(phen)2p-MOPIP] $\left.\left(\mathrm{PF}_{6}\right)_{2} \cdot 2 \mathrm{H}_{2} \mathrm{O}\right)$, an anticancer complex with significant anticancer activity and strong auto-fluorescence, was encapsulated in this nanosystem. ${ }^{21,22}$ The nanosystem overcame the poor stability and low solubility of $\mathrm{Ru}(\mathrm{POP})$. It was also $\mathrm{pH}$ responsive and targeted, and the cellular uptake of the drug was greatly improved. This mUPR@Ru(POP) had strong suppressive effects against VEGF-induced angiogenesis through apoptosis. It also significantly inhibited VEGFinduced human umbilical vein endothelial cell (HUVEC) migration, invasion, and tube formation both in vitro and in vivo. These findings have provided meaningful insights into the development of antiangiogenesis drugs.

\section{Materials and methods}

RGD was obtained from China Gier Biochemistry Company (Shanghai, China). NIPAM, mPEG, $N$-hydroxysuccinimide (NHS), 1-ethyl-3-(3-dimethylaminopropyl) carbodiimide hydrochloride (EDC), ammonium persulfate (APS), 2-mercapto benzoic acid (MBA), methyl thiazolyl tetrazolium (MTT), propidium iodide(PI), 4',6-diamidino-2-phenylindole (DAPI), and dihydroethidium (DHE) were purchased from Sigma-Aldrich Co., St Louis (MO, USA). Tetraethylorthosilicate (TEOS), polyethyleneimine (PEI, 99\%), triethanolamine, and hexadecyltrimethylammonium bromide (CTAB, 99\%) were obtained from Aladdin Chemistry Company (Shanghai, China). The HUVECs were purchased from Guangzhou Jennio Biotech Co., Ltd. (Guangzhou, China).

\section{Preparation of $U$. lactuca polysaccharide}

U. lactuca powder was purchased from Research Center of Hydrobiology of Jinan University (Guangzhou, China). To extract the polysaccharide, the sample powder was refluxed with ethanol in a water bath for $2 \mathrm{~h}$. Then, the precipitate was heated at $100^{\circ} \mathrm{C}$ in water $(\mathrm{pH}=4)$ for another $2 \mathrm{~h}$. The filtrate was lyophilized, and the polysaccharide was obtained.

\section{Synthesis of mUPR@Ru(POP)}

First, NIPAM $(0.5 \mathrm{~g})$ and UL polysaccharide $(0.25 \mathrm{~g})$ were dissolved in deionized water, and then stirred overnight. Afterward, $0.025 \mathrm{~g}$ of MBA was added, and the mixture was heated at $75^{\circ} \mathrm{C}$ in a three-necked flask with nitrogen gas. Heating of the mixture was continued after the addition of $0.025 \mathrm{~g}$ of APS at $60^{\circ} \mathrm{C}$ for $4 \mathrm{~h}$. After centrifuging and lyophilizing, UL polysaccharide-NIPAM (UP) was obtained. Second, mPEG was decorated to the surface of UP by dissolving UP (500 mg) in water, adding NHS (100 mg), EDC (100 mg), and mPEG (100 mg), and reacting at room temperature for $24 \mathrm{~h}$. mPEG-UL polysaccharide-NIPAM (mUP) was obtained after dialysis for $24 \mathrm{~h}$. Furthermore, NHS, EDC, and RGD were added and stirred for 24 h. mPEG-UL polysaccharide-NIPAM-RGD (mUPR) was obtained after $24 \mathrm{~h}$ of dialysis. Finally, Ru(POP) was encapsulated in mUPR to form mUPR@Ru(POP) by the reaction of mUPR and $\mathrm{Ru}(\mathrm{POP})$ for $24 \mathrm{~h}$.

\section{Characterization}

The morphology, particle size, and zeta potential of mUPR@ $\mathrm{Ru}(\mathrm{POP})$ were characterized by transmission electron microscopy (TEM; H-7650; Hitachi Ltd., Tokyo, Japan) and Nano-ZS instrument (Malvern Instruments, Malvern, UK). The Fourier transform infrared (FTIR; Equinox 55; Bruker, Ettlingen, Germany) spectroscopy was conducted in the range of $4,000-500 \mathrm{~cm}^{-1}$. 


\section{Cell culture and MTT assay}

The HUVECs were cultured in F12 medium including 10\% fetal bovine serum (FBS), $0.01 \%$ streptomycin, and $1 \%$ penicillin in $5 \% \mathrm{CO}_{2}$ atmosphere at $37^{\circ} \mathrm{C}$. To perform MTT assay, 2,000 cells/well of HUVECs were seeded in a 96-well plate for $24 \mathrm{~h}$, and different concentrations of mUPR@Ru(POP) were added and incubated for $72 \mathrm{~h}$. Next, $30 \mu \mathrm{L}$ of MTT was added to each well for $3 \mathrm{~h}$, and then the medium was replaced with dimethyl sulfoxide (DMSO). The cell viability of HUVECs was measured by the absorbance at $570 \mathrm{~nm}$ with a microplate spectrophotometer.

\section{In vitro intracellular fluorescence localization}

In brief, 20,000 cells $/ \mathrm{mL}$ of HUVECs were seeded in $2 \mathrm{~cm}$ dishes and cultured for $24 \mathrm{~h}$. Next, the mUPR@Ru(POP) was added at different time points. The DAPI and LysoTracker were added preceding the observation time of $0.5 \mathrm{~h}$ and $2 \mathrm{~h}$. Finally, the cells were washed with PBS three times and observed by fluorescence microscopy (IX51; Olympus Corporation, Tokyo, Japan).

\section{In vitro cell migration}

HUVECs were seeded and incubated in six-well plates for $24 \mathrm{~h}$. Monolayer cells were wounded by $100 \mu \mathrm{L}$ pipette tips and washed with PBS three times. Fresh medium and mUPR@Ru(POP) were added and incubated for $24 \mathrm{~h}$. Then, the migrated cells were photographed and quantified by manual counting.

\section{In vitro cell invasion}

The Boyden chamber is a useful tool to study the effects of mUPR@Ru(POP) on HUVEC invasion. Briefly, the Boyden chamber was precoated with matrigel for $6 \mathrm{~h}$ at $37^{\circ} \mathrm{C}$. HUVECs $\left(5 \times 10^{4}\right.$ cells $\left./ \mathrm{mL}\right)$ with serum-free medium were placed in the upper compartment and were allowed to migrate into the lower compartment, in which mUPR@Ru(POP) was present with F12 medium. Nonmigratory cells were scraped off $24 \mathrm{~h}$ later, and migratory cells were fixed in methanol, washed, and stained with Giemsa solution. Experiments were performed in triplicate transwells, and the number of cells that migrated to the lower side of the membrane was determined.

\section{In vitro tube formation assay and chorioallantoic membrane assay}

The effects of mUPR@Ru(POP) on tube formation and chorioallantoic membrane were evaluated as reported. ${ }^{17}$ Briefly, Matrigel was first thawed at $4^{\circ} \mathrm{C}$ overnight. Then, $100 \mu \mathrm{L}$ Matrigel per well was added into prechilled 48-well plate and incubated for $30 \mathrm{~min}$ at $37^{\circ} \mathrm{C}$ to allow the gel to solidify. HUVECs $\left(5 \times 10^{4}\right.$ cells $\left./ \mathrm{mL}\right)$ were added into the matrigel layer, as well as mUPR@Ru(POP).After $8 \mathrm{~h}$, the tube formation was visualized under an Olympus microscope (Olympus Corporation, Tokyo, Japan). The chorioallantoic membrane (CAM) assay was used to analyze the effect of mUPR@Ru(POP) on angiogenesis in vivo. First, the fertilized eggs were cleaned with $75 \%$ ethanol and incubated at $37^{\circ} \mathrm{C}$ in an egg incubator for 5 days. Then, the eggs were cracked open, and different concentrations of mUPR@Ru(POP), with or without VEGF, were gently injected on the chorioallantoic membrane. After the embryos were incubated for another 2 days, the CAM was observed under an Olympus microscope.

\section{Flow cytometric analysis}

As described in our previous paper, ${ }^{18}$ the Beckman flow cytometry was used to analyze the cell cycle distribution.

\section{Statistical analysis}

Experiments were repeated at least three times. The differences between the treatment groups were analyzed by one-way ANOVA multiple comparisons using SPSS 13.0 statistical package (SPSS Inc., Chicago, IL, USA).

\section{Results and discussion Characterization of mUPR@Ru(POP)}

In this study, a novel cancer-targeting nanosystem, mUPR@ $\mathrm{Ru}(\mathrm{POP})$, was designed and synthesized (Scheme 1). The polyelectrolyte core was constructed by utilizing the polymerization of NIPAM and UL polysaccharide with APS as an initiator and MBA as a crosslinker, followed by surface modification with $\mathrm{MPEG}$ and RGD peptide. According to the previous research, ${ }^{23}$ the decoration of $\mathrm{mPEG}$ increased the solubility, stability, and biocompatibility of the nanosystem. Moreover, RGD was a cancer-targeting ligand. Then, this drug delivery system (mUPR) was loaded with anticancer drug Ru(POP) to form mUPR@Ru(POP) (Figure 1A and B). The average particle size of mUPR@Ru(POP) was shown in Figure 1C and D. As shown in Figure 1D, the average particle size of mUPR@Ru(POP) was 250 nm, which was approximately the TEM result as shown in Figure 1C. The TEM showed the image of homogeneous particles with a diameter of about $200 \mathrm{~nm}$, and the nanosystems were stable in 40 days (Figure S1). To determine the stability of mUPR@ $\mathrm{Ru}(\mathrm{POP})$, the particle sizes in DMEM and DMEM with $10 \%$ FBS were observed (Figure 1E). The results showed that the particle sizes had little changes within $24 \mathrm{~h}$ in both media. Moreover, the nanoparticles were stable with a diameter of about $300 \mathrm{~nm}$ after 30 days. FTIR spectra (Figure 1F) were 


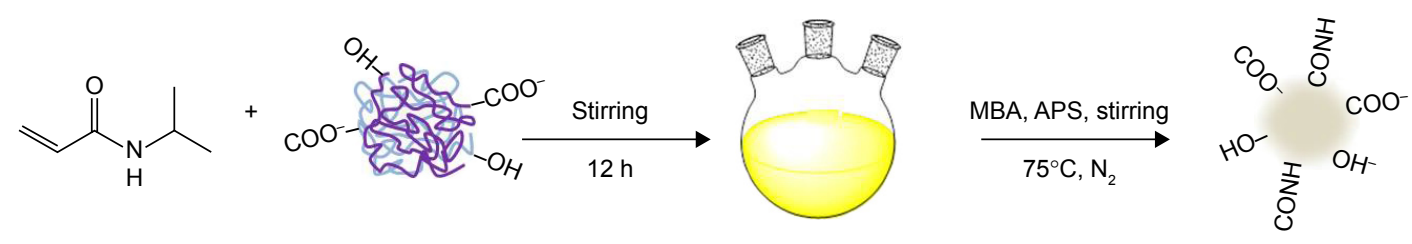

NIPAM UL polysaccharide

UP
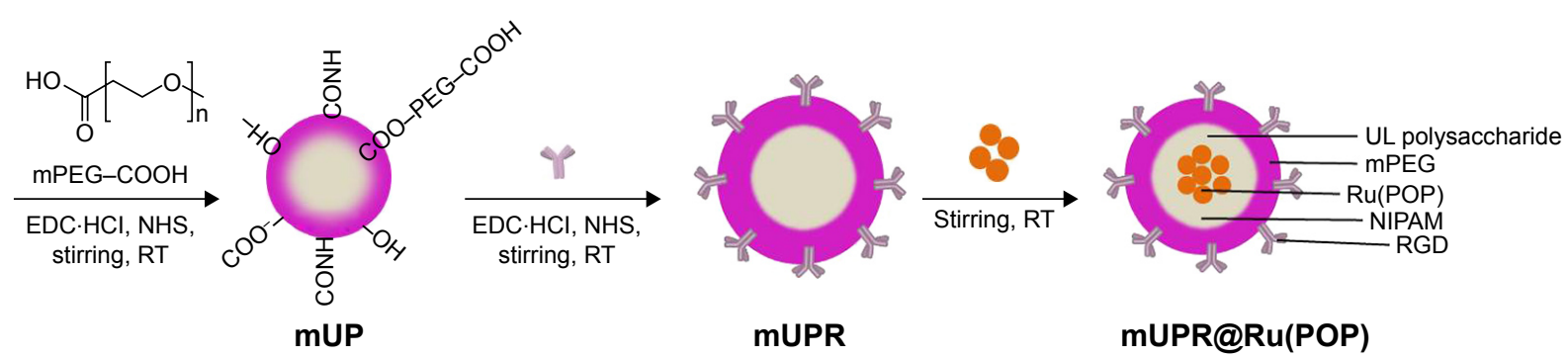

P RGD Loaded drug: Ru(POP)

Scheme I Scheme of synthesis of mUPR@Ru(POP).

Abbreviations: APS, ammonium persulfate; EDC, I-ethyl-3-(3-dimethylaminopropyl) carbodiimide hydrochloride; MBA, 2-mercapto benzoic acid; mPEG, methoxy polyethylene glycol; mUPR, mPEG-UL polysaccharide-NIPAM-RGD; NHS, N-hydroxysuccinimide; NIPAM, N-isopropyl acrylamide; RGD, Arg-Gly-Asp; RT, room temperature; Ru(POP), $[\mathrm{Ru}(\mathrm{Phen}) 2 \mathrm{P}-\mathrm{MOPIP}]\left(\mathrm{PF}_{6}\right)_{2} \cdot 2 \mathrm{H}_{2} \mathrm{O}$; UL, Ulva lactuca; UP, UL polysaccharide-NIPAM.

used to further characterize the mUPR@Ru(POP) nanosystem. As shown in Figure $1 \mathrm{~F}(\mathrm{a})$, the peaks at $1,243 \mathrm{~cm}^{-1}$ and $1,180 \mathrm{~cm}^{-1}$ were contributed to the symmetrical stretching vibration of $\mathrm{C}-\mathrm{O}-\mathrm{C}$ and the stretching vibration of $\mathrm{C}-\mathrm{N}$ from $\mathrm{Ru}(\mathrm{POP})$. These two peaks were also presented in the spectrum of mUPR@Ru(POP) (Figure 1F[d]). The peaks at $1,540 \mathrm{~cm}^{-1}$ and $1,380 \mathrm{~cm}^{-1}$ were the $\mathrm{NH}$ bending for secondary amides and isopropyl group bending vibrations of NIPAM (Figure $1 \mathrm{~F}[\mathrm{~b}-\mathrm{d}]$ ). The peak at $1,600 \mathrm{~cm}^{-1}$ corresponded to the stretching vibration of amide from RGD (Figure $1 \mathrm{~F}[\mathrm{c}$ and $\mathrm{d}]$ ). The difference and appearance of the abovementioned peaks indicated the successful synthesis of mUPR@Ru(POP).

\section{$\mathrm{pH}$ response of $\mathrm{mUPR} @ \mathrm{Ru}(\mathrm{POP})$}

Four $\mathrm{pH}$ buffer solutions were used to demonstrate the $\mathrm{pH}$ responsive swelling of the mUPR@Ru(POP) nanosystem (Figure 2A-F). The $\mathrm{pH} 7.4$ was similar to the $\mathrm{pH}$ of normal tissues and organs; $\mathrm{pH} 6.8$ was the $\mathrm{pH}$ of cytoplasm in cancer cells; $\mathrm{pH} 6.2$ was the $\mathrm{pH}$ of tumor extracellular environment; $\mathrm{pH} 5.3$ was the $\mathrm{pH}$ in lysosome. ${ }^{20}$ The zeta potential and particle size of mUPR@Ru(POP) in different buffer solutions are shown in Figure 2A and D. When the $\mathrm{pH}$ decreased from 7.4 to 5.3 , the particle size increased from $250 \mathrm{~nm}$ to $950 \mathrm{~nm}$, and the surface charge changed from $-25 \mathrm{mV}$ to $+10 \mathrm{mV}$ (Figure 2A). TEM (Figure 2B) and a scheme (Figure 1A) were used to further illustrate the $\mathrm{pH}$ response of the nanosystem. The TEM images showed that the diameter of the particles was about $200 \mathrm{~nm}$ at $\mathrm{pH}$ 7.4. However, the diameter of the nanoparticles expanded to about $800 \mathrm{~nm}$ when the $\mathrm{pH}$ decreased to 5.3 (Figure 2D). Under acidic conditions, there was a change in the ionization state due to the presence of carboxyl and amine group in the nanosystem. This produced an electrostatic repulsion between nanoparticles, ${ }^{24}$ resulting in the swelling of the polyelectrolyte core and the change of particle size. In vitro drug release of $\mathrm{Ru}(\mathrm{POP})$ was also performed in different $\mathrm{pH}$ values. As shown in Figure 2E, after $48 \mathrm{~h}$, the drug release was about $85 \%$ at $\mathrm{pH} 5.3$, which was almost three times more than that at pH 7.4. Therefore, this mUPR@Ru(POP) nanosystem had pH-responsive property which greatly increased the drug release in lysosome.

\section{Intracellular localization and cellular uptake of mUPR@Ru(POP)}

It was reported that pharmaceutical activity of nanomedicine is mostly dependent on the efficiency of cellular uptake and drug delivery. ${ }^{22}$ The quantitative cellular uptake in HUVECs was originally determined (Figure 2C). HUVECs were treated with $10 \mu \mathrm{g} / \mathrm{mL}$ of Ru(POP), mUP@Ru(POP), and mUPR@Ru(POP). The concentrations of Ru(POP) were detected by inductively coupled plasma mass spectrometry (ICP-MS). The results showed that the intracellular drugs were time dependent. The intracellular concentrations of mUPR@Ru(POP) were the highest, and the intracellular concentrations of $\mathrm{Ru}(\mathrm{POP})$ were the lowest. Moreover, Figure $2 \mathrm{~F}$ 
A

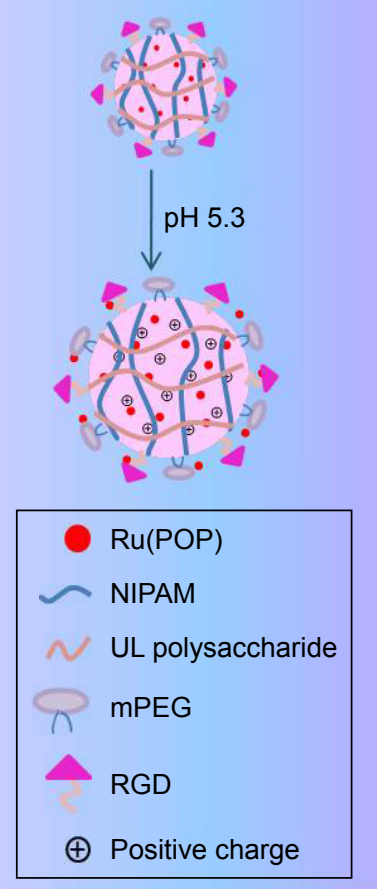

B
Angiogenesis inhibition

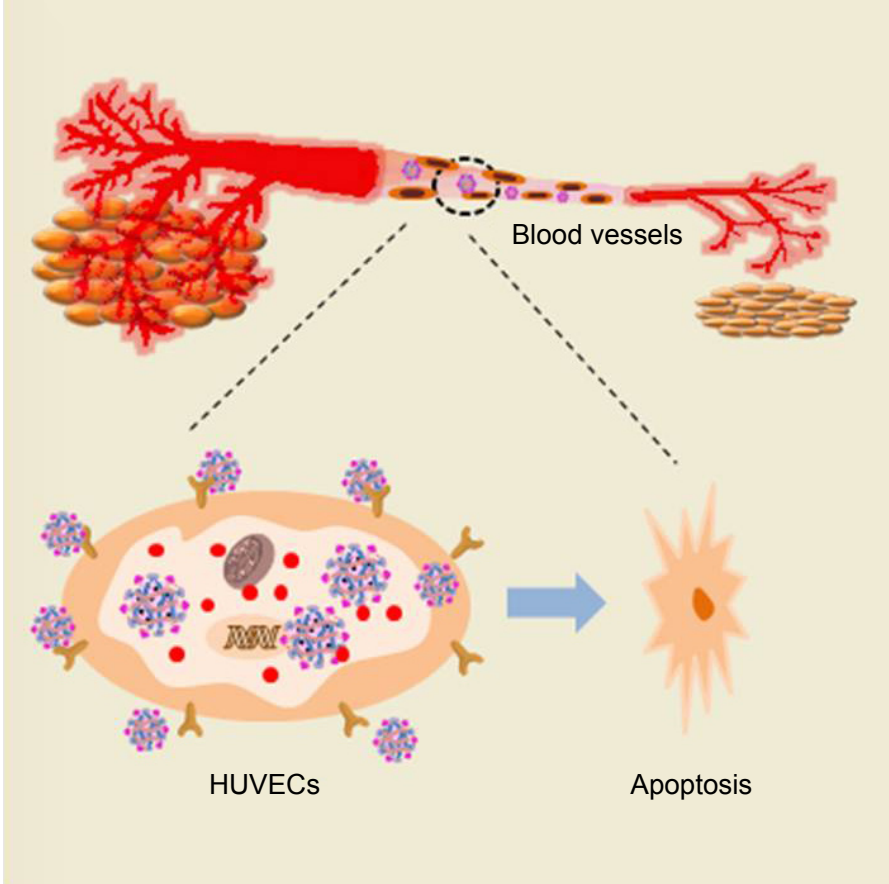

C
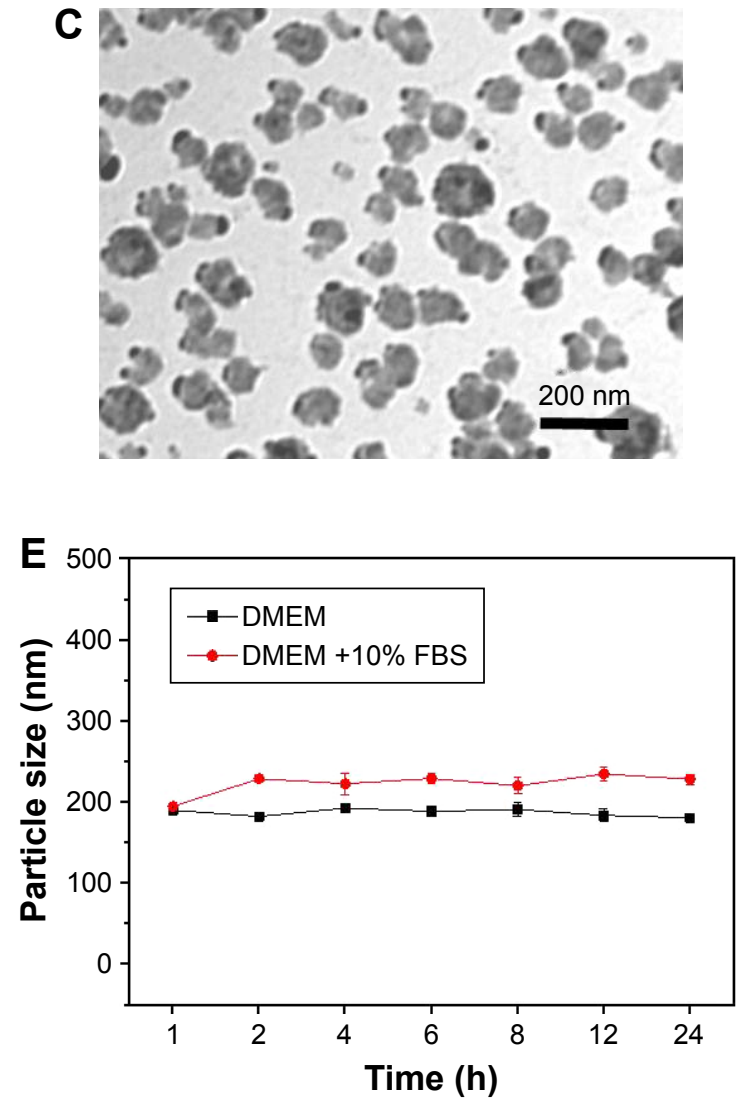

D

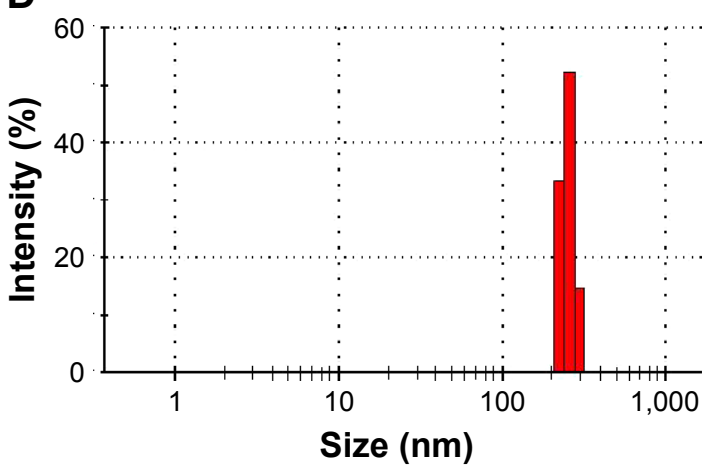

$\mathbf{F}$

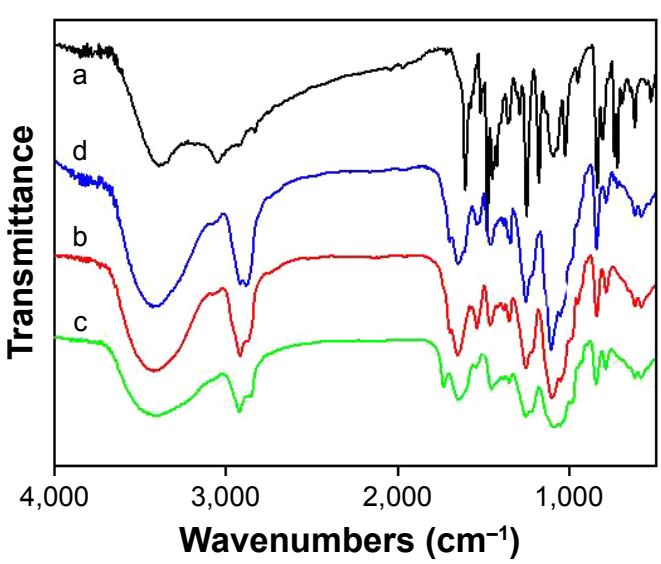

Figure I (A, B) Design, delivery, and action mechanisms of bioresponsive cancer-targeted polysaccharide nanosystem to inhibit angiogenesis. (C) TEM images of mUPR@ Ru(POP). (D) Size distribution of mUPR@Ru(POP). (E) Changes in the particle size of mUPR@Ru(POP) following incubation with DMEM or I0\% FBS; (F) FTIR spectra of (a) Ru(POP), (b) UP, (c) mUPR, and (d) mUPR@Ru(POP).

Abbreviations: FBS, fetal bovine serum; FTIR, Fourier transform infrared; HUVEC, human umbilical vein endothelial cell; mPEG, methoxy polyethylene glycol; mUPR, mPEG-UL polysaccharide-NIPAM-RGD; NIPAM, N-isopropyl acrylamide; RGD, Arg-Gly-Asp; TEM, transmission electron microscopy; Ru(POP), [Ru(phen)2p-MOPIP] $\left(\mathrm{PF}_{6}\right)_{2} \cdot 2 \mathrm{H}_{2} \mathrm{O}$; UL, Ulva lactuca; UP, UL polysaccharide-NIPAM. 
A
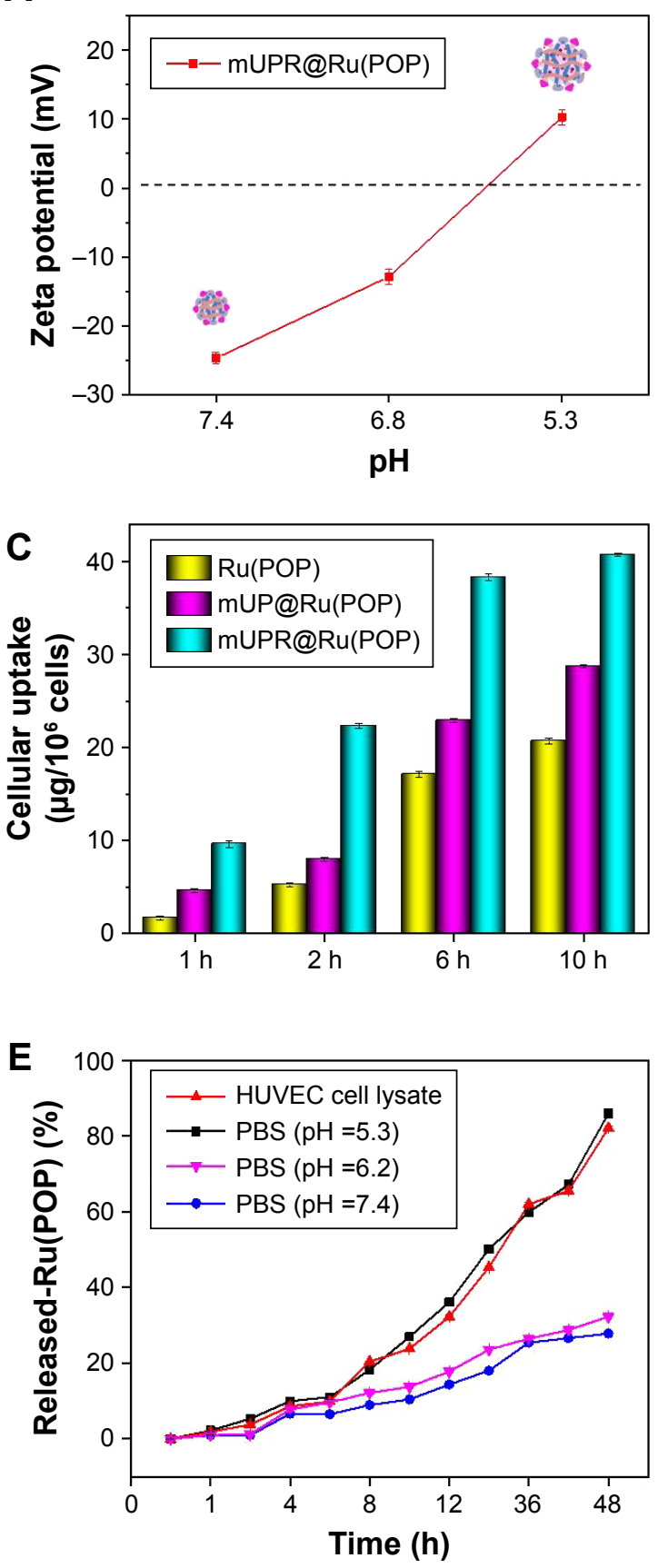

B
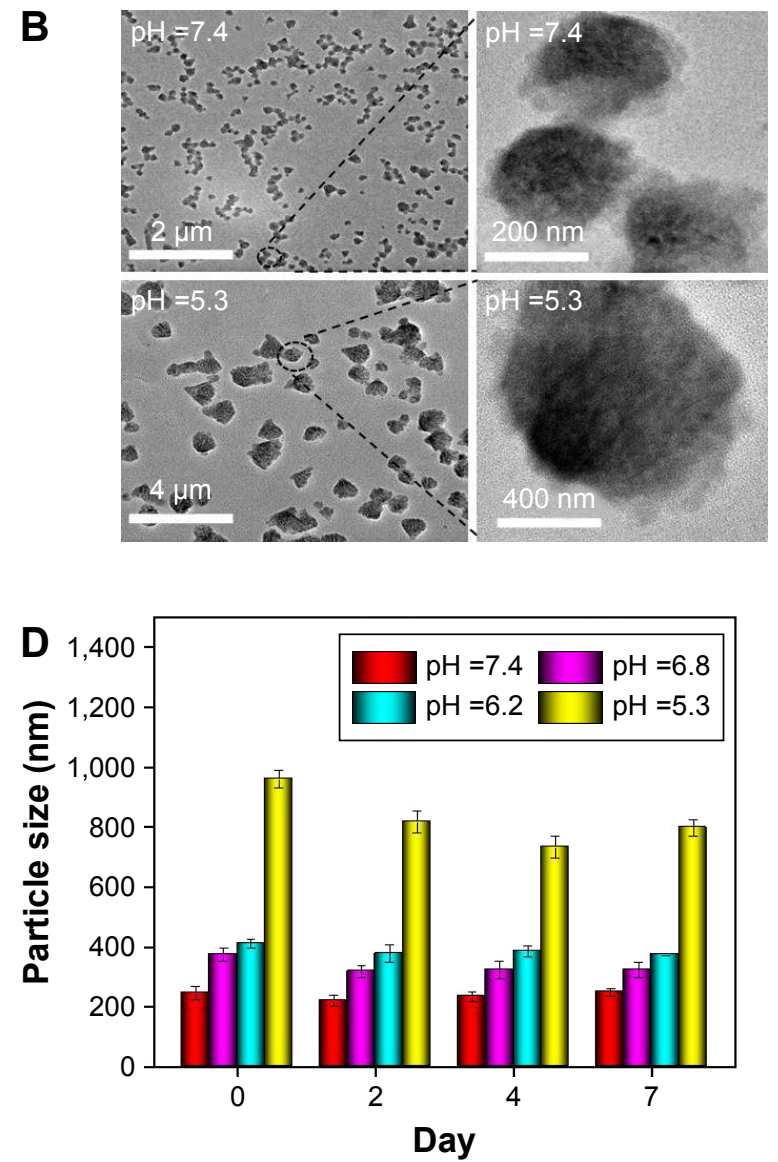

$\mathbf{F}$

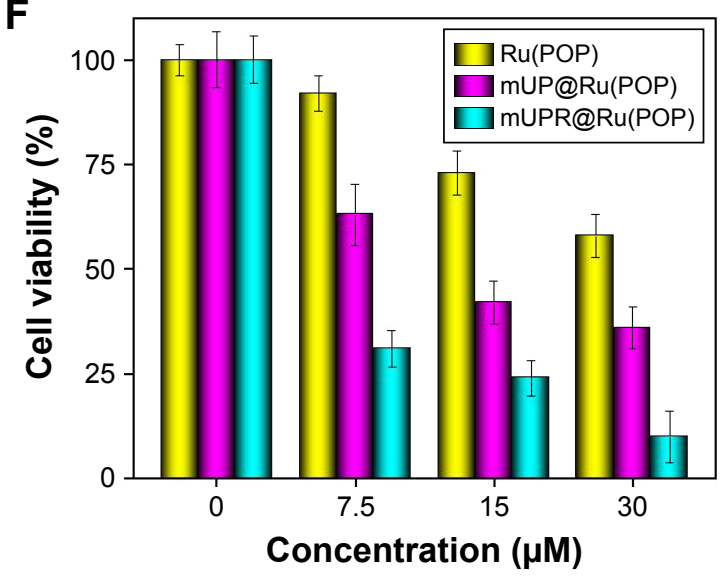

Figure 2 (A) Zeta potential of mUPR@Ru(POP) at different pH values. (B) TEM images of mUPR@Ru(POP) at pH 7.4 and 5.3. (C) Quantitative cellular uptake of Ru(POP), mUP@Ru(POP), and mUPR@Ru(POP) in HUVECs $\left(2 \times 10^{5}\right.$ cells $\left./ \mathrm{mL}\right)$. HUVECs were treated with Ru(POP) $(10 \mu \mathrm{g} / \mathrm{mL}), \mathrm{mUP} @ \mathrm{Ru}(\mathrm{POP})(\mathrm{I} 0 \mu \mathrm{g} / \mathrm{mL})$, and $\mathrm{mUPR} @ \mathrm{Ru}(\mathrm{POP})$ $(10 \mu \mathrm{g} / \mathrm{mL})$ for different periods of time. The concentrations of Ru(POP) were determined by ICP-MS. (D) Change in the particle size of mUPR@Ru(POP) with pH value. (E) In vitro drug release of Ru(POP) from mUPR@Ru(POP) in different solution. (F) The cell viability of HUVECs treated with different concentrations of Ru(POP), mUP@ $\mathrm{Ru}(\mathrm{POP})$, and mUPR@Ru(POP) for 72 h. Each value represents mean $\pm \mathrm{SD}(\mathrm{n}=3)$.

Abbreviations: HUVEC, human umbilical vein endothelial cell; ICP-MS, inductively coupled plasma mass spectrometry; mPEG, methoxy polyethylene glycol; mUP, mPEG-UL polysaccharide-NIPAM; mUPR, mPEG-UL polysaccharide-NIPAM-RGD; NIPAM, N-isopropyl acrylamide; RGD, Arg-Gly-Asp; Ru(POP), [Ru(phen)2p-MOPIP](PF $)_{2} \cdot 2 \mathrm{H}_{2} \mathrm{O}$; TEM, transmission electron microscopy; UL, Ulva lactuca.

also shows the significant differences of cell viability induced by Ru(POP), mUP@Ru(POP), and mUPR@Ru(POP). The abovementioned results suggested that mUPR@Ru(POP) had a high cellular uptake, and the decoration with RGD as a target molecule greatly enhanced the antiangiogenic activity of mUPR@Ru(POP). Intracellular fluorescence localization was carried out to further investigate whether mUPR@Ru(POP) was in lysosome. As shown in Figure 3, the localization was studied by using Lyso-Tracker (red) to label lysosomes and DAPI to label the nucleus. The overlay results indicated that the drug successfully entered the cells through the lysosomes after treatment for $2 \mathrm{~h}$. 


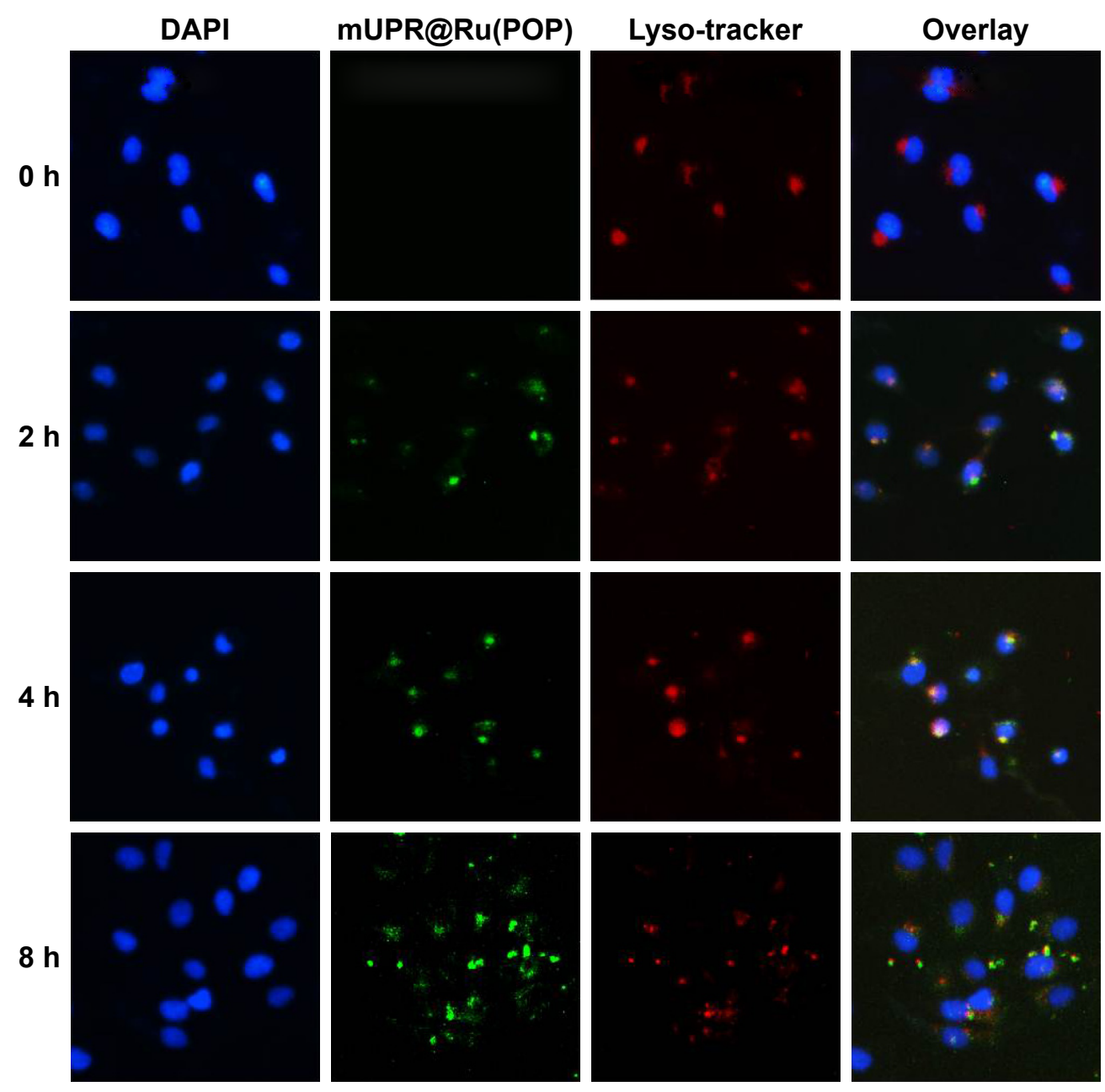

Figure 3 Colocalization of mUPR@Ru(POP) (green fluorescence), Lyso-Tracker (red fluorescence), and DAPI (blue fluorescence) in HUVECs with an observation period of $8 \mathrm{~h}$.

Abbreviations: DAPI, 4',6-diamidino-2-phenylindole; HUVECs, human umbilical vein endothelial cells; mPEG, methoxy polyethylene glycol; mUPR, mPEG-UL polysaccharideNIPAM-RGD; NIPAM, N-isopropyl acrylamide; RGD, Arg-Gly-Asp; Ru(POP), [Ru(phen)2p-MOPIP](PF $)_{2} \cdot 2 \mathrm{H}_{2} \mathrm{O}$; UL, Ulva lactuca.

\section{mUPR@Ru(POP) inhibited VEGF-} induced cell migration, invasion, and tube formation in vitro

The early stages of angiogenesis have three steps: endothelial cell proliferation, migration, and tube formation. ${ }^{5}$ To determine whether mUPR@Ru(POP) could suppress the VEGF-induced endothelial cell migration and tube formation, wound healing, Transwell assay, and tube formation assay were performed. As shown in Figures $4 \mathrm{~A}$ and $\mathrm{B}$ and $\mathrm{S} 2$, at the concentration of $1 \mu \mathrm{M}, \mathrm{Ru}(\mathrm{POP}), \mathrm{mUP} @ \mathrm{Ru}(\mathrm{POP})$ and mUPR@Ru(POP) all strongly inhibited VEGF-induced migration and invasion of HUVECs, but the ability of mUPR@Ru(POP) was the highest. As shown in Figures 4C and $\mathrm{S} 3$, tube formation assay was performed to further evaluate the antiangiogenic ability of mUPR@Ru(POP). As expected, VEGF promoted the formation of elongated tube-like structures, but Ru(POP), mUP@Ru(POP), and
mUPR@Ru(POP) inhibited the tube formation. Moreover, mUPR@Ru(POP) had the strongest inhibition. Overall, the relative reduced numbers of the migrated cells and invaded cells, as well as the relative decreased length of capillary tube, suggested the significant antiangiogenic ability of mUPR@Ru(POP).

\section{mUPR@Ru(POP) inhibited VEGF-induced CAM angiogenesis}

The chick CAM assay is a powerful in vivo angiogenesis model and permits a realistic evaluation of the angiogenic response. ${ }^{22}$ The abovementioned results showed that mUPR@Ru(POP) inhibited VEGF-induced tube formation in vitro. Therefore, CAM assay was used to further assess the antiangiogenesis of mUPR $@ \mathrm{Ru}(\mathrm{POP})$ in vivo. As shown in Figures 4D and S4, the formation of branched blood vessels was promoted by VEGF, but mUPR@Ru(POP) 

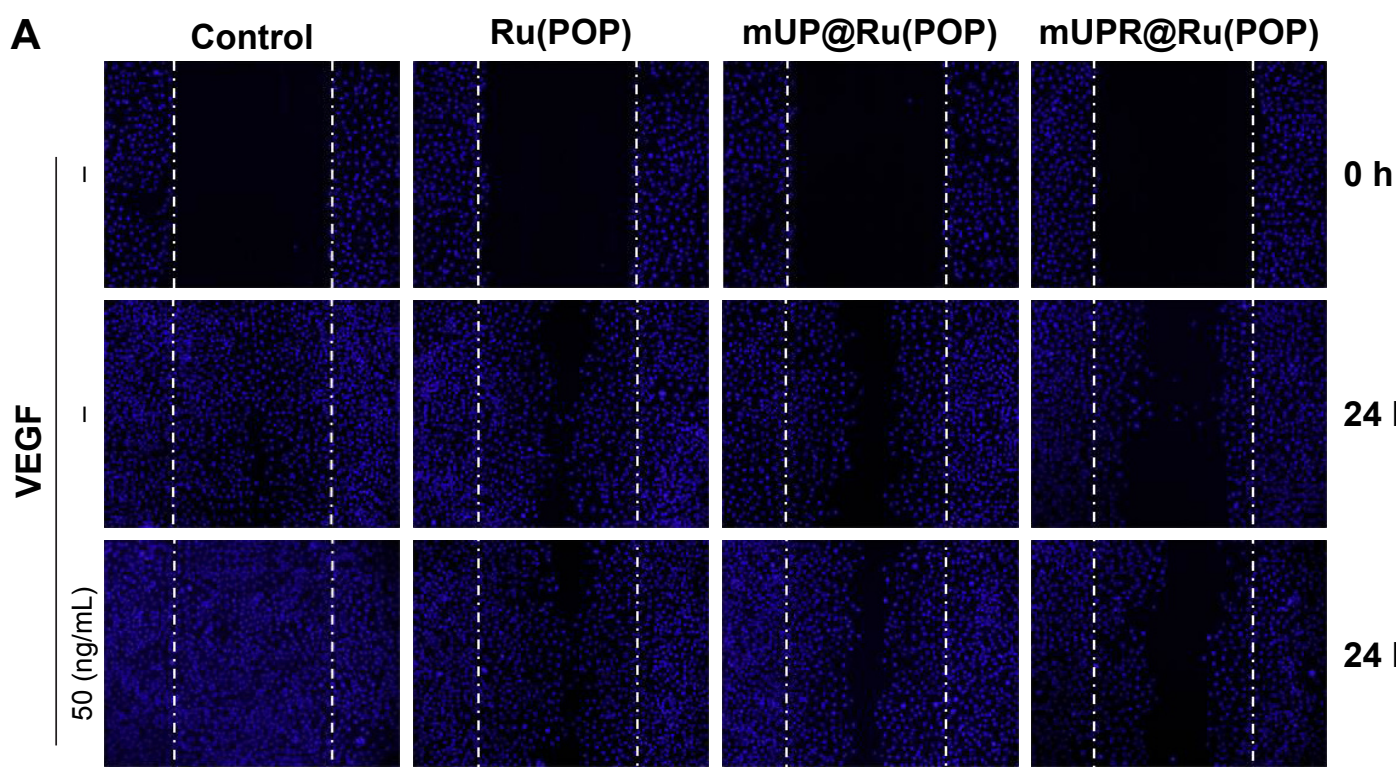

$24 \mathrm{~h}$
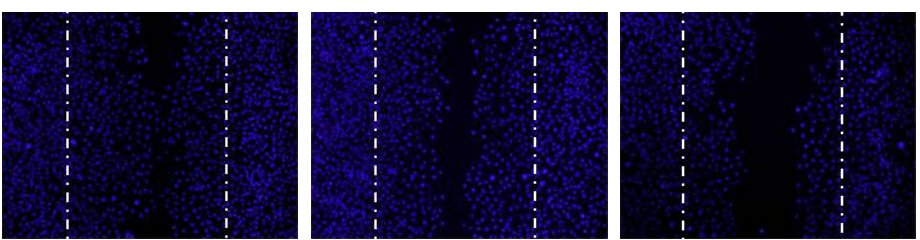

$24 \mathrm{~h}$
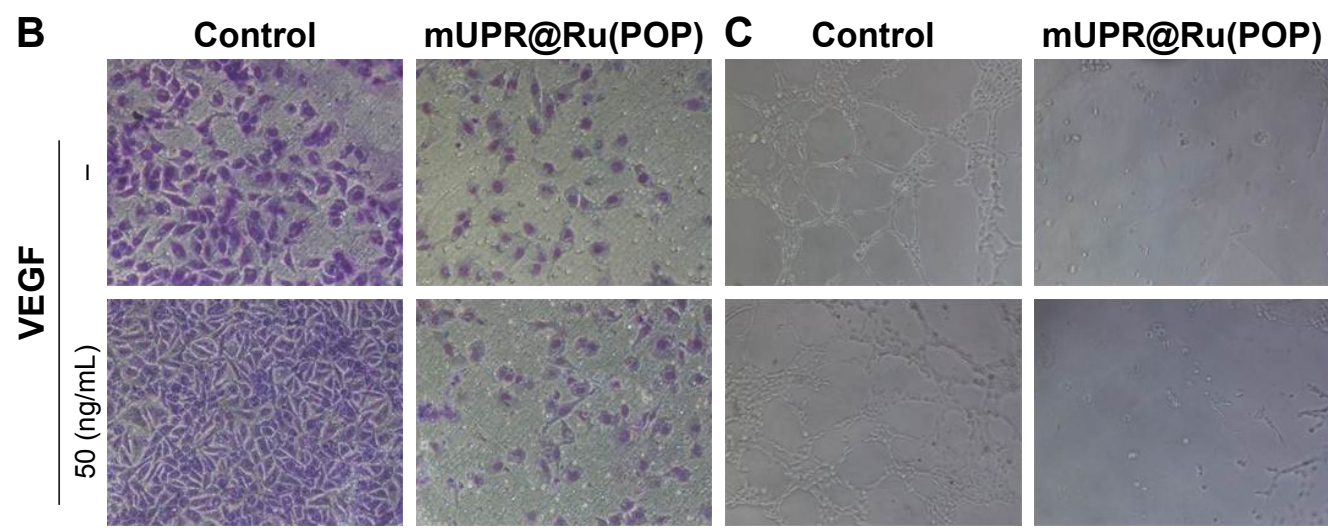

D

Control
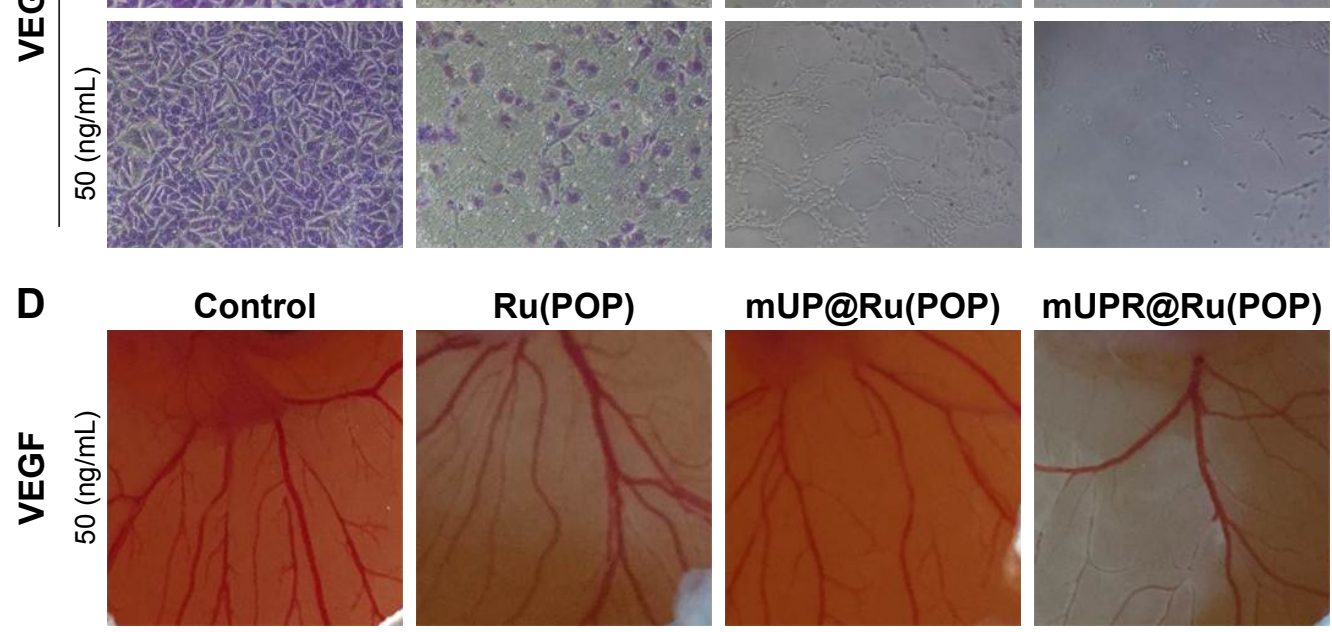

mUPR@Ru(POP)

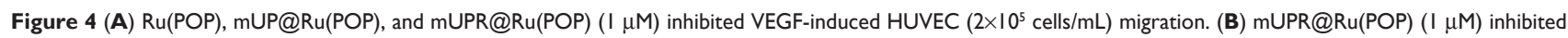
VEGF-induced HUVEC $\left(5 \times 10^{4}\right.$ cells $\left./ \mathrm{mL}\right)$ invasion. (C) Antiangiogenesis assay mUPR@Ru(POP) $(\mathrm{I} \mu \mathrm{M})$ on HUVECs $\left(5 \times 10^{4} \mathrm{cells} / \mathrm{mL}\right)$. (D) Representative images of angiogenesis inhibition of Ru(POP), mUP@Ru(POP), and mUPR@Ru(POP) $(30 \mu \mathrm{M})$ in CAM assay with VEGF.

Abbreviations: CAM, chorioallantoic membrane; HUVEC, human umbilical vein endothelial cell; mPEG, methoxy polyethylene glycol; mUP, mPEG-UL polysaccharideNIPAM; mUPR, mPEG-UL polysaccharide-NIPAM-RGD; NIPAM, N-isopropyl acrylamide; RGD, Arg-Gly-Asp; UL, Ulva lactuca; Ru(POP), [Ru(phen)2p-MOPIP](PF $)_{2} \cdot 2 \mathrm{H}_{2} \mathrm{O}$; VEGF, vascular endothelial growth factor.

showed a dose-dependent reduction in the branched vessels. Compared to Ru(POP) and mUP@Ru(POP),mUPR@ $\mathrm{Ru}(\mathrm{POP})$ demonstrated the highest activity. These results suggested that mUPR@Ru(POP) inhibited VEGF-induced CAM angiogenesis.

\section{Apoptosis induced by mUPR@Ru(POP)}

The mUPR@Ru(POP) nanosystem showed strong suppressive effects against VEGF-induced angiogenesis. So, the effects of synthesized drugs on the cell cycle and apoptosis were analyzed by flow cytometry. After $72 \mathrm{~h}$ of incubation with $7.5 \mu \mathrm{M}, 15 \mu \mathrm{M}$ and $30 \mu \mathrm{M}$ of mUPR@Ru(POP), the representative DNA histograms (Figure 5) showed a significant increase from $21.9 \%$ and $46.7 \%$ to $58.8 \%$ in the sub-G1 peaks, respectively (Figure S5). When comparing the activity of Ru(POP), mUP@Ru(POP), and mUPR@ $\mathrm{Ru}(\mathrm{POP})$ at the same concentration of $30 \mu \mathrm{M}, \mathrm{mUPR} @$ $\mathrm{Ru}(\mathrm{POP})$ was the highest. These results indicated that 


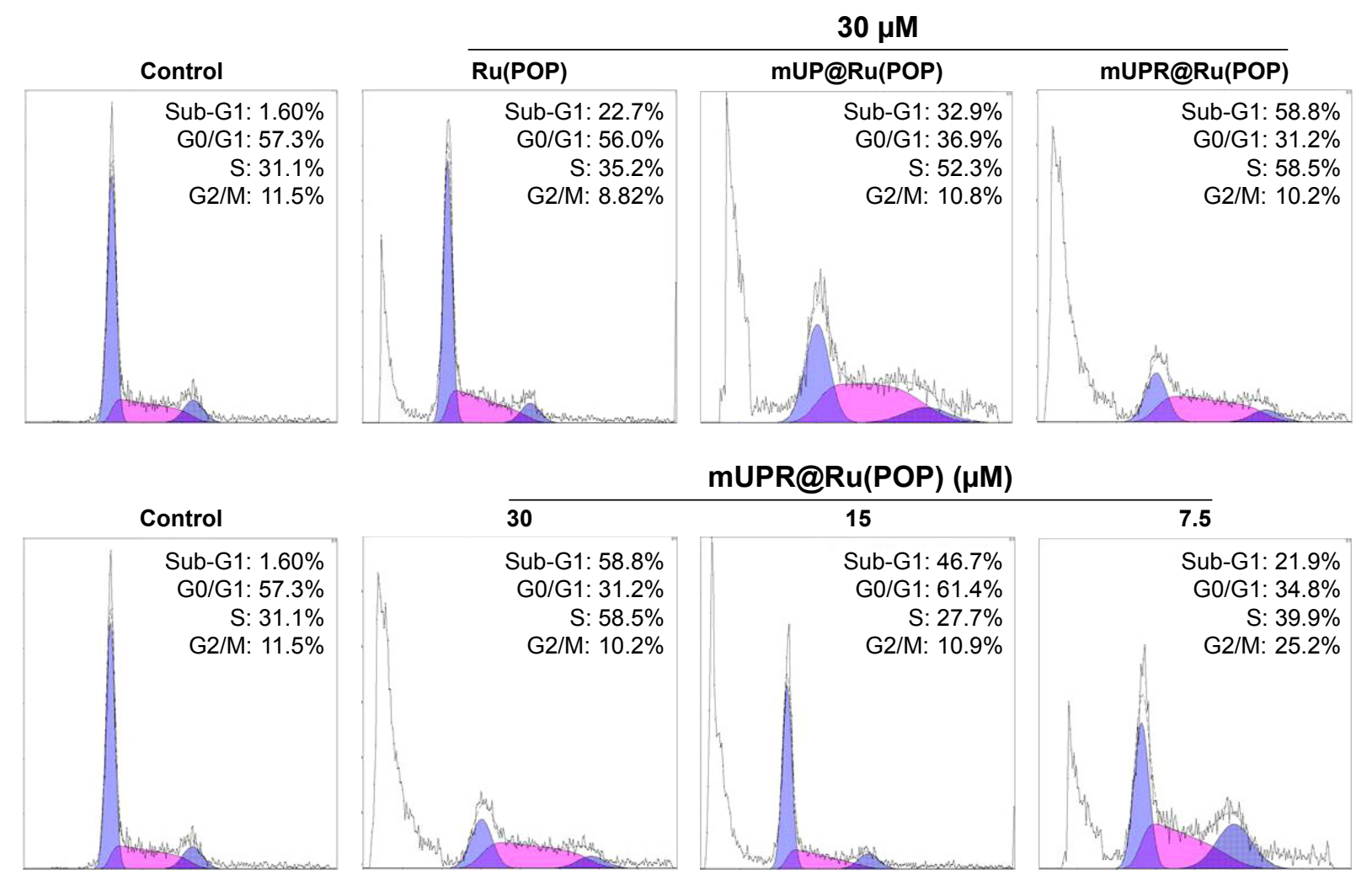

Figure 5 Effects of Ru(POP), mUP@Ru(POP), and mUPR@Ru(POP) on HUVEC cycle distribution for 72 h.

Abbreviations: HUVEC, human umbilical vein endothelial cell; $\mathrm{mPEG}$, methoxy polyethylene glycol; $\mathrm{mUP}$, mPEG-UL polysaccharide-NIPAM; $m$ UPR, mPEG-UL polysaccharideNIPAM-RGD; NIPAM, N-isopropyl acrylamide; RGD, Arg-Gly-Asp; UL, Ulva lactuca; $\mathrm{Ru}(\mathrm{POP})$, [Ru(phen)2p-MOPIP] $\left(\mathrm{PF}_{6}\right)_{2} \cdot 2 \mathrm{H}_{2} \mathrm{O}$.

suppressive effects induced by mUPR@Ru(POP) were mainly through apoptosis.

\section{Conclusion}

We successfully synthesized an antiangiogenic mUPR@, $\mathrm{Ru}(\mathrm{POP})$ nanosystem with the decoration of $\mathrm{mPEG}$ and RGD peptide, which improved both the $\mathrm{pH}$ response and the cellular uptake of the mUPR@Ru(POP) nanosystem. The targeted mUPR@Ru(POP) could swell in an acidic environment and efficiently release $\mathrm{Ru}(\mathrm{POP})$ drug in the lysosome of HUVECs. Moreover, the mUPR@Ru(POP) had strong suppressive effects against VEGF-induced angiogenesis through apoptosis. The mUPR@Ru(POP) significantly inhibited VEGF-induced HUVEC migration and tube formation both in vitro and in vivo. These results have provided new and meaningful insights into the antiangiogenic effects of mUPR@Ru(POP) nanosystem.

\section{Acknowledgment}

This work was supported by the Natural Science Foundation of China (21401076, 21271002), National High Technology Research and Development Program of China (863 Program, SS2014AA020538), Science Foundation for Distinguished
Young Scholars (S2013050014667) of Guangdong Province, Foundation for High-level Talents in Higher Education of Guangdong, YangFan Innovative \& Entrepreneurial Research Team Project (201312H05), Guangdong Special Support Program, and Guangdong Frontier and Key Technological Innovation Special Funds.

\section{Disclosure}

The authors report no conflicts of interest in this work.

\section{References}

1. Siegel RL, Miller KD, Jemal A. Cancer statistics, 2017. CA: A Cancer Journal for Clinicians. 2017;67(1):7-30.

2. DeVita VT, Chu E. A history of cancer chemotherapy. Cancer Res. 2008;68(21):8643-8653.

3. Saha B, Haldar U, De P. Polymer-chlorambucil drug conjugates: a dynamic platform of anticancer drug delivery. Macromol Rapid Commun. 2016;37(13):1015-1020.

4. Johnson RP, Jeong YI, John JV, et al. Lipo-poly(L-histidine) hybrid materials with $\mathrm{pH}$-sensitivity, intracellular delivery efficiency, and intrinsic targetability to cancer cells. Macromol Rapid Commun. 2014;35(9): 888-894.

5. Sousa EHS, Ridnour LA, Gouveia FS, et al. Thiol-activated HNO release from a ruthenium antiangiogenesis complex and HIF-1 $\alpha$ inhibition for cancer therapy. ACS Chem Biol. 2016;11(7):2057-2065.

6. Chen Y, Gao F, Sha X, Fang X. Dual-functional C(RGDYK)-decorated pluronic micelles for antiangiogenesis and drug resistant tumor treatment in vitro. Nanomed Nanotechnol. 2016;12(2):501. 
7. Folkman J. Antiangiogenesis in cancer therapy - endostatin and its mechanisms of action. Exp Cell Res. 2006;312(5):594-607.

8. Samant RS, Shevde LA. Recent advances in anti-angiogenic therapy of cancer. Oncotarget. 2011;2(3):122-134.

9. Ivanova V, Rouseva R, Kolarova M, Serkedjieva J, Rachev R, Manolova N. Isolation of a polysaccharide with antiviral effect from Ulva lactuca. Prep Biochem. 1994;24(2):83-97.

10. Nie S, Xing Y, Kim GJ, Simons JW. Nanotechnology applications in cancer. Annu Rev Biomed Eng. 2007;9:257-288.

11. Sathivel A, Raghavendran HR, Srinivasan P, Devaki T. Anti-peroxidative and anti-hyperlipidemic nature of Ulva lactuca crude polysaccharide on D-galactosamine induced hepatitis in rats. Food Chem Toxicol. 2008;46(10):3262-3267.

12. Naito H, Wakabayashi T, Kidoya H, et al. Endothelial side population cells contribute to tumor angiogenesis and antiangiogenic drug resistance. Cancer Res. 2016;76(11):3200-3210.

13. Jayson GC, Kerbel R, Ellis LM, Harris AL. Antiangiogenic therapy in oncology: current status and future directions. Lancet. 2016; 388(10043):518-529.

14. Siemann DW, Chaplin DJ, Horsman MR. Vascular-targeting therapies for treatment of malignant disease. Cancer. 2004;100(12):2491-2499.

15. Kerbel RS, Kamen BA. The anti-angiogenic basis of metronomic chemotherapy. Nat Rev Cancer. 2004;4(6):423-436.

16. Maeda Y, Pittella F, Nomoto T, et al. Fine-tuning of charge-conversion polymer structure for efficient endosomal escape of siRNA-loaded calcium phosphate hybrid micelles. Macromol Rapid Commun. 2014; 35(13):1211-1215.
17. Hu H, You Y, He L, et al. The rational design of NAMI-A-loaded mesoporous silica nanoparticles as antiangiogenic nanosystems. $J$ Mater Chem B. 2015;3(30):6338-6346.

18. Jiang W, Fu Y, Yang F, et al. Gracilaria lemaneiformis polysaccharide as integrin-targeting surface decorator of selenium nanoparticles to achieve enhanced anticancer efficacy. ACS Appl Mater Interfaces. 2014;6(16):13738-13748.

19. Peer D, Karp JM, Hong S, Farokhzad OC, Margalit R, Langer R. Nanocarriers as an emerging platform for cancer therapy. Nat Nanotechnol. 2007;2(12):751-760.

20. Fu XY, Yang YH, Li XL, et al. RGD peptide-conjugated selenium nanoparticles: antiangiogenesis by suppressing VEGF-VEGFR2-ERK/ AKT pathway. Nanomedicine. 2016;12(6):1627-1639.

21. Chen T, Liu Y, Zheng WJ, Liu J, Wong YS. Ruthenium polypyridyl complexes that induce mitochondria-mediated apoptosis in cancer cells. Inorg Chem. 2010;49(14):6366-6368.

22. Sun DD, Liu YN, Yu QQ, et al. The effects of luminescent ruthenium(II) polypyridyl functionalized selenium nanoparticles on bFGF-induced angiogenesis and AKT/ERK signaling. Biomaterials. 2013;34(1): 171-180.

23. Fang XY, Jiang WT, Huang YY, et al. Size changeable nanosystems for precise drug controlled release and efficient overcoming of cancer multidrug resistance. J Mater Chem B. 2017;5(5):944-952.

24. Kuhn W, Hargitay B, Katchalsky A, Eisenberg H. Reversible dilation and contraction by changing the state of Ionization of high-polymer acid networks. Nature. 1950;165(4196):514-516. 


\section{Supplementary materials}

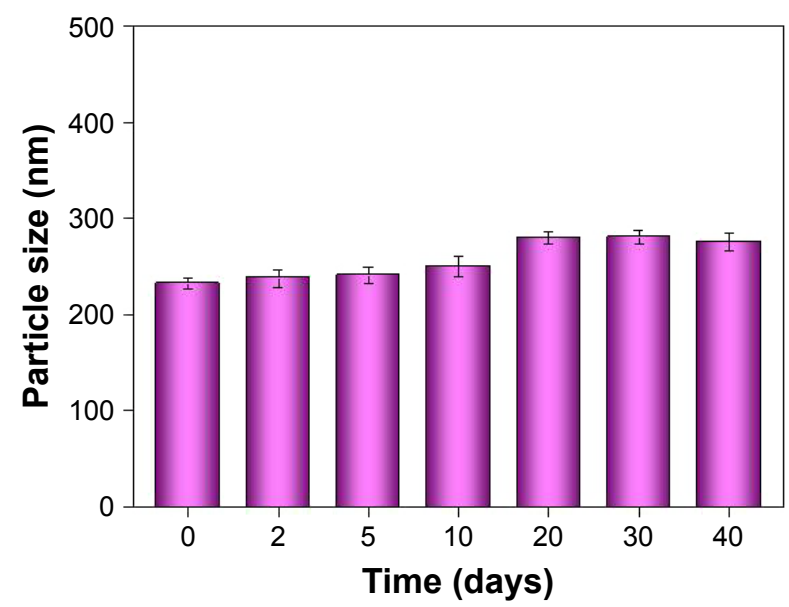

Figure SI The particle size of mUPR@Ru(POP) in 40 days.

Abbreviations: mPEG, methoxy polyethylene glycol; mUPR, mPEG-UL polysaccharide-NIPAM-RGD; NIPAM, N-isopropyl acrylamide; RGD, Arg-Gly-Asp; Ru(POP), $[\mathrm{Ru}(\mathrm{Phen}) 2 \mathrm{p}-\mathrm{MOPIP}]\left(\mathrm{PF}_{6}\right)_{2} \cdot 2 \mathrm{H}_{2} \mathrm{O} ; \mathrm{UL}$, Ulva lactuca.

A

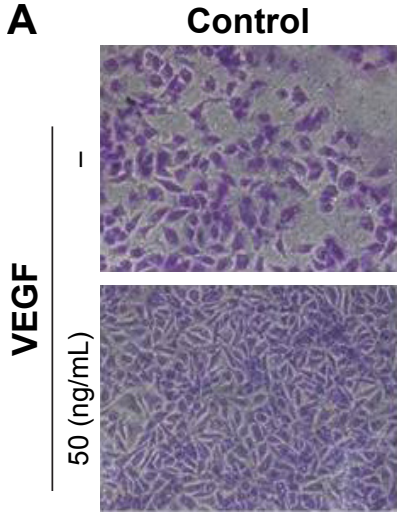

B

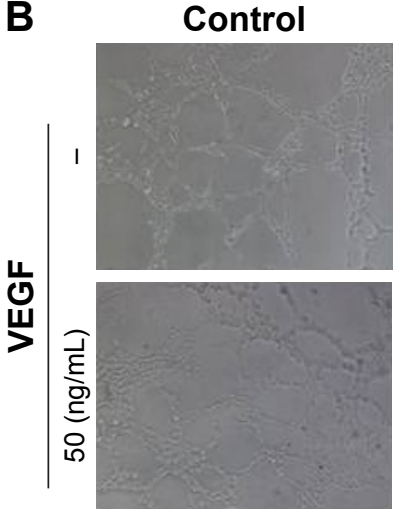

$\mathrm{Ru}(\mathrm{POP})$
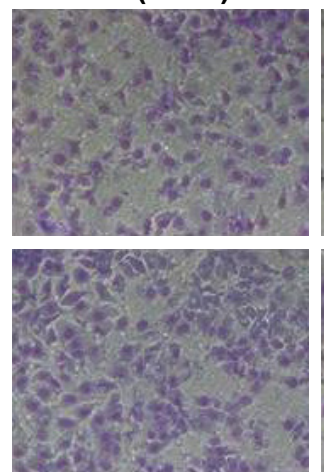

$\mathrm{Ru}(\mathrm{POP})$
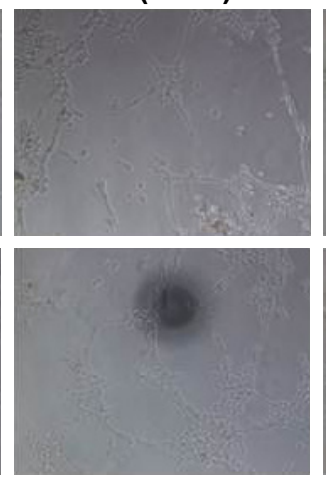

mUP@Ru(POP)
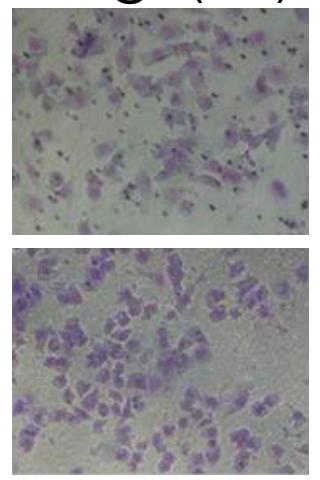

mUP@Ru(POP)
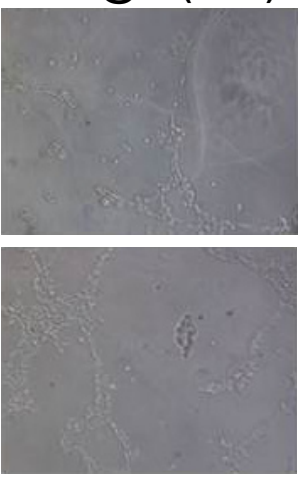

mUPR@Ru(POP)
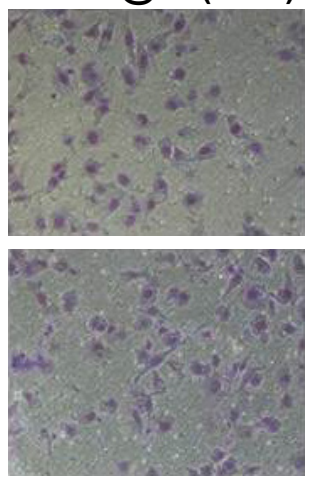

mUPR@Ru(POP)
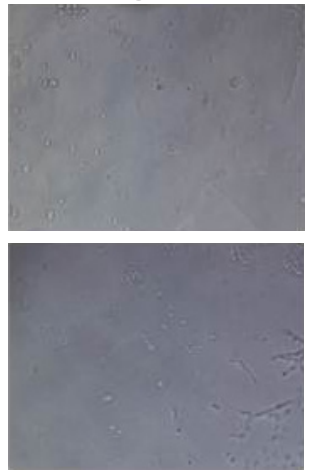

Figure S2 (A) Ru(POP), mUP@Ru(POP), and mUPR@Ru(POP) $(\mathrm{I} \mu \mathrm{M})$ inhibited VEGF-induced HUVEC $\left(5 \times 10^{4}\right.$ cells $\left./ \mathrm{mL}\right)$ invasion. (B) Antiangiogenesis assay of Ru(POP), mUP@Ru(POP), and mUPR@Ru(POP) $(I \mu M)$ on HUVECs $\left(5 \times 10^{4}\right.$ cells $\left./ \mathrm{mL}\right)$.

Note: Magnification is 100X.

Abbreviations: HUVEC, human umbilical vein endothelial cell; $m P E G$, methoxy polyethylene glycol; mUP, mPEG-UL polysaccharide-NIPAM; mUPR, mPEG-UL polysaccharideNIPAM-RGD; NIPAM, N-isopropyl acrylamide; RGD, Arg-Gly-Asp; Ru(POP), [Ru(phen)2p-MOPIP](PF $)_{2} \cdot 2 \mathrm{H}_{2} \mathrm{O}$; UL, Ulva lactuca; VEGF, vascular endothelial growth factor. 


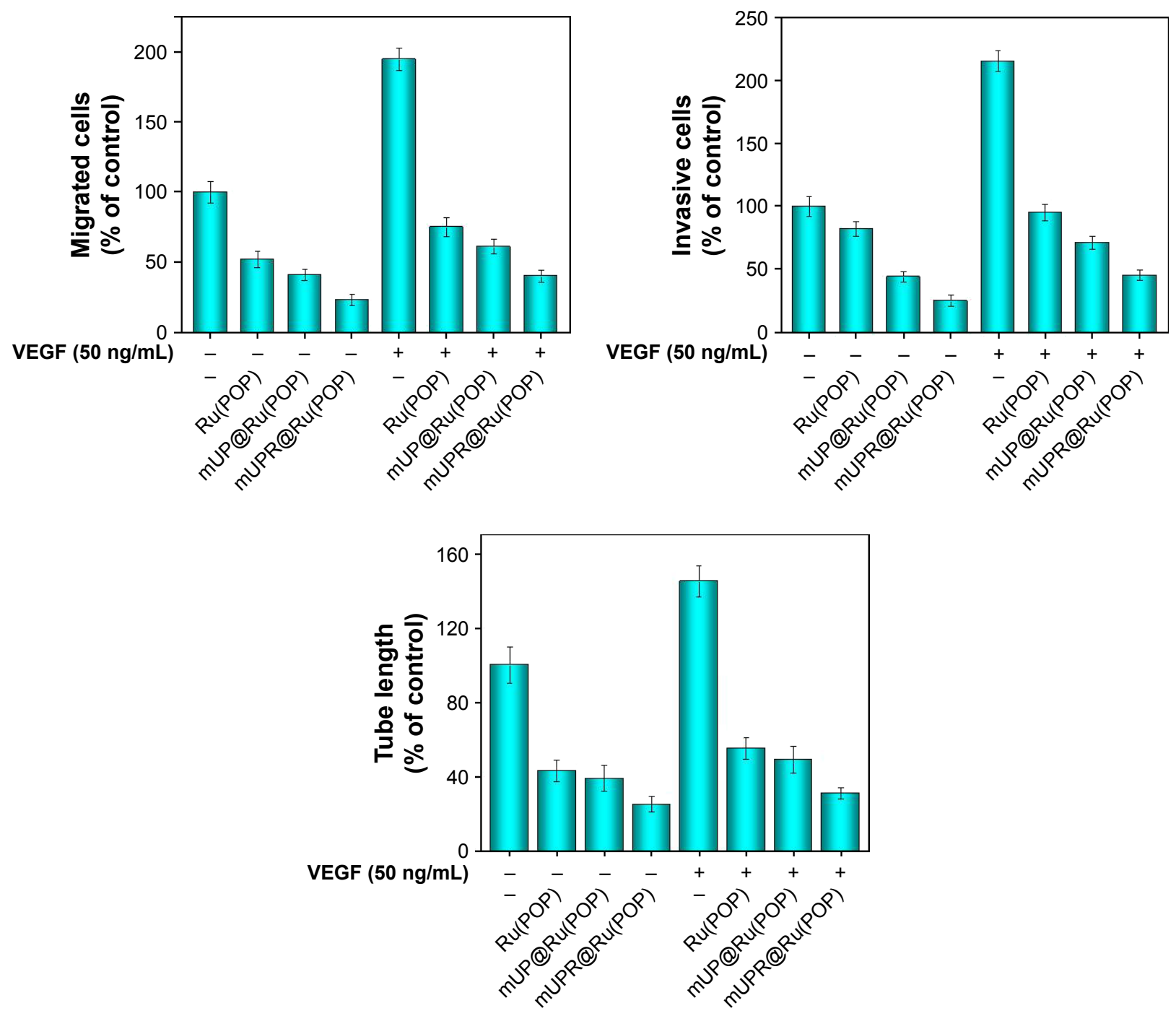

Figure S3 The relative reduction in the migrated cell numbers, invaded cell numbers, and capillary tube length suggested remarkable anti-metastasis effect of Ru(POP), mUP@Ru(POP), and mUPR@Ru(POP).

Note: The quantitative data were analyzed by manual counting (\% of control).

Abbreviations: mPEG, methoxy polyethylene glycol; mUP, mPEG-UL polysaccharide-NIPAM; mUPR, mPEG-UL polysaccharide-NIPAM-RGD; NIPAM, N-isopropyl acrylamide; RGD, Arg-Gly-Asp; $\mathrm{Ru}(\mathrm{POP})$, [Ru(phen)2p-MOPIP] $\left(\mathrm{PF}_{6}\right)_{2} \cdot 2 \mathrm{H}_{2} \mathrm{O}$; UL, Ulva lactuca; VEGF, vascular endothelial growth factor. 

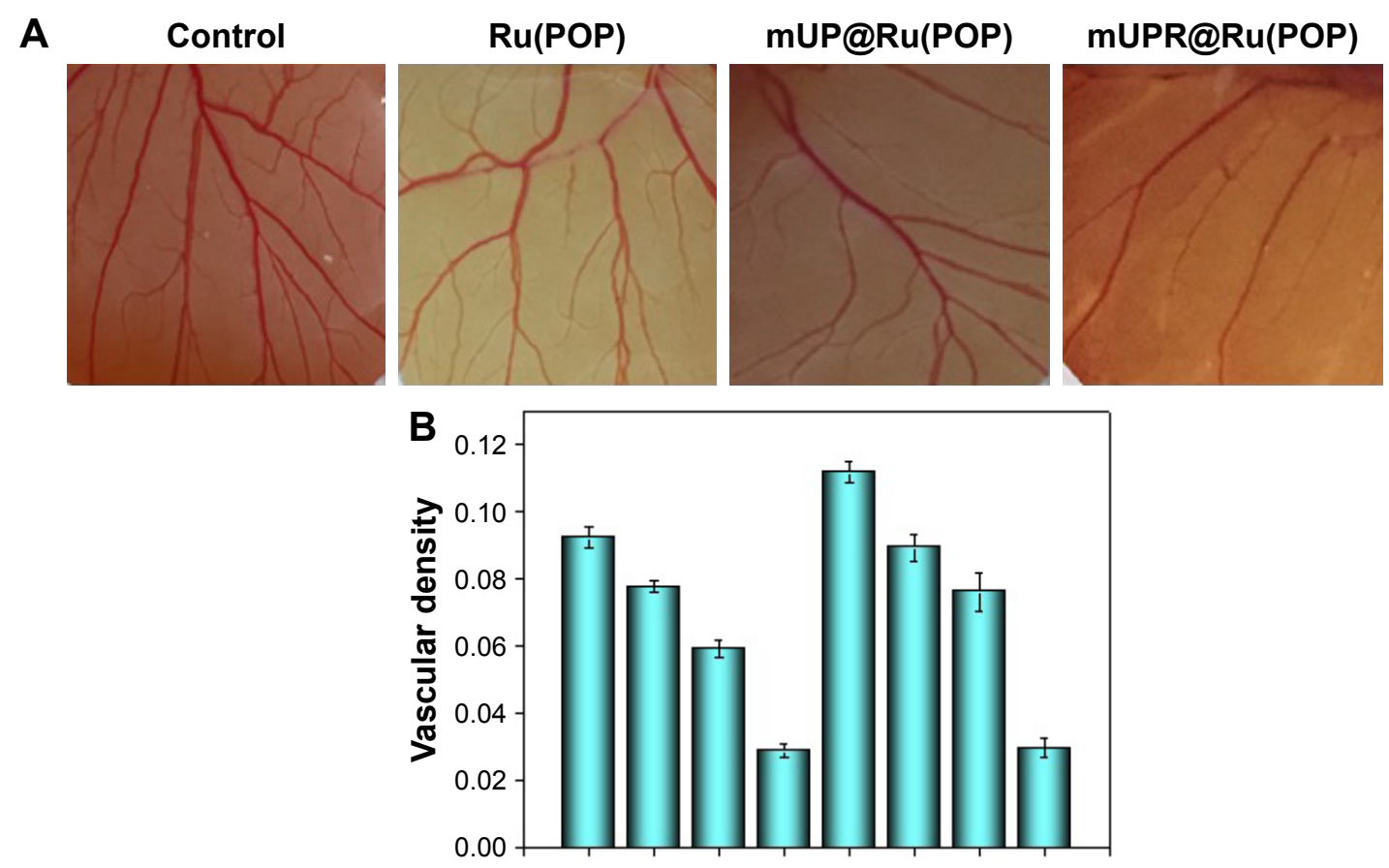

VEGF $(50 \mathrm{ng} / \mathrm{mL})$
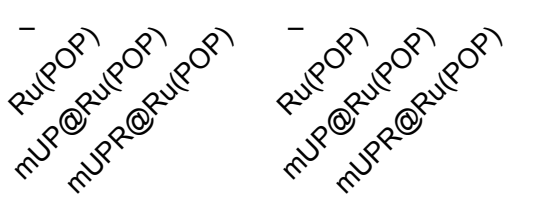

Figure S4 (A) Representative images of angiogenesis inhibition of Ru(POP), mUP@Ru(POP), and mUPR@Ru(POP) (30 $\mu M)$ in CAM assay without VEGF. (B) The relative quantitation of vascular density based on the CAM images.

Abbreviations: CAM, chorioallantoic membrane; mPEG, methoxy polyethylene glycol; mUP, mPEG-UL polysaccharide-NIPAM; mUPR, mPEG-UL polysaccharide-NIPAMRGD; NIPAM, N-isopropyl acrylamide; RGD, Arg-Gly-Asp; Ru(POP), [Ru(phen)2p-MOPIP](PF $)_{2} \cdot 2 \mathrm{H}_{2} \mathrm{O}$; UL, Ulva lactuca; VEGF, vascular endothelial growth factor.
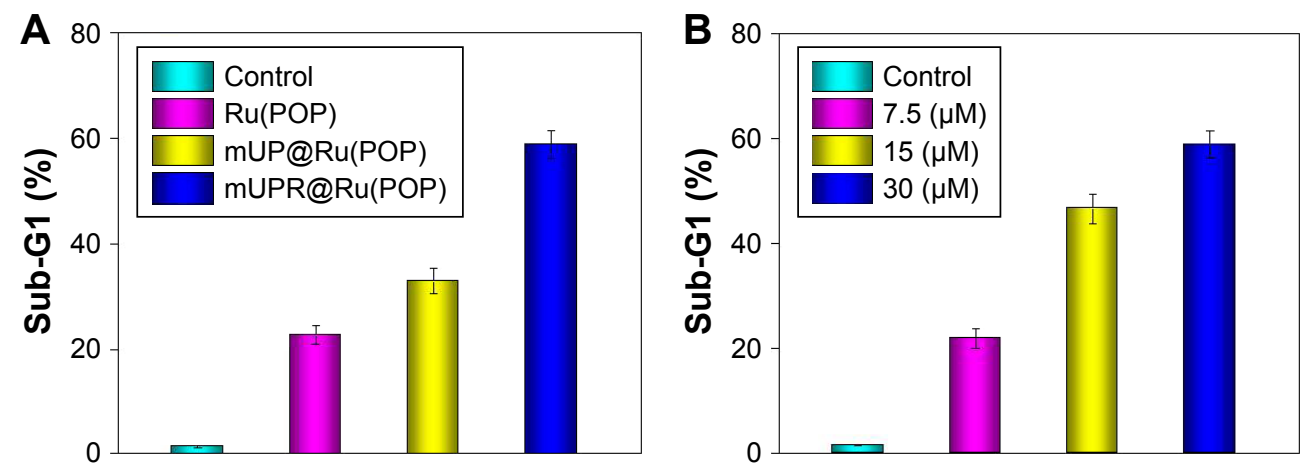

Figure S5 Analysis of sub-GI value obtained from flow cytometry.

Notes: (A) Effects of Ru(POP), mUP@Ru(POP), and mUPR@Ru(POP) on HUVEC cycle distribution for 72 h. (B) Effects of different concentrations of mUPR@Ru(POP) on HUVEC cycle distribution for $72 \mathrm{~h}$.

Abbreviations: HUVEC, human umbilical vein endothelial cell; mPEG, methoxy polyethylene glycol; mUP, mPEG-UL polysaccharide-NIPAM; mUPR, mPEG-UL polysaccharideNIPAM-RGD; NIPAM, N-isopropyl acrylamide; RGD, Arg-Gly-Asp; Ru(POP), [Ru(phen)2p-MOPIP](PF $)_{2} \cdot 2 \mathrm{H}_{2} \mathrm{O}$; UL, Ulva lactuca.

International Journal of Nanomedicine

\section{Publish your work in this journal}

The International Journal of Nanomedicine is an international, peerreviewed journal focusing on the application of nanotechnology in diagnostics, therapeutics, and drug delivery systems throughout the biomedical field. This journal is indexed on PubMed Central, MedLine, CAS, SciSearch $\AA$, Current Contents ${ }^{\circledR} /$ Clinical Medicine,

Journal Citation Reports/Science Edition, EMBase, Scopus and the Elsevier Bibliographic databases. The manuscript management system is completely online and includes a very quick and fair peer-review system, which is all easy to use. Visit http://www.dovepress.com/ testimonials.php to read real quotes from published authors.

Submit your manuscript here: http://www.dovepress.com/international-journal-of-nanomedicine-journal 